\title{
Comparison of intravenous paracetamol vs. intramuscular diclofenac for postoperative pain control in abdominal hysterectomy
}

\author{
Poonam Bisht*, Geeta Jain
}

Department of Obstetrics and Gynecology, Government Medical College, Haldwani, Uttarakhand, India

Received: 21 January 2021

Accepted: 02 March 2021

*Correspondence:

Dr. Poonam Bisht,

E-mail: drpoonamgangola@gmail.com

Copyright: (C) the author(s), publisher and licensee Medip Academy. This is an open-access article distributed under the terms of the Creative Commons Attribution Non-Commercial License, which permits unrestricted non-commercial use, distribution, and reproduction in any medium, provided the original work is properly cited.

\begin{abstract}
Background: Abdominal hysterectomy is one of the most common gynaecological surgery conducted worldwide. It is commonly associated with post operative pain. The aim of this study was Comparison of intravenous Paracetamol versus intramuscular Diclofenac for postoperative pain control in abdominal hysterectomy. Objectives of this study were to compare the effectiveness of intravenous Paracetamol and intramuscular Diclofenac when used for postoperative pain control in abdominal hysterectomy patients and to compare the need for rescue analgesia in both the groups.

Methods: It's a prospective observational and clinically randomized study conducted in Department of Obstetrics and Gynaecology, Government Medical College Haldwani and associated Dr. Shushila Tiwari Government Hospital, Haldwani consisting of 120 patients undergoing abdominal hysterectomy. 60 patients in group A received Paracetamol $1000 \mathrm{mg}$ (100ml infusion) intravenous followed by subsequent doses of $1000 \mathrm{mg}$ every 8 hourly for 48 hrs and another 60 patients in group B received injection Diclofenac $75 \mathrm{mg}$ intramuscular every 8 hourly for $48 \mathrm{hrs}$. Pain intensity of patients was noted 2 hourly for 6 hours after giving the first dose of the drug and then at every 8 hour for next 48 hours, using VAS scoring. Patient's hemodynamics in form of respiratory rate, heart rate, mean arterial pressure (MAP), oxygen saturation (sPO2) were monitored as per pain monitoring protocol.

Results: Post-op mean VAS score at different point of time among the two treatment groups was lower for Paracetamol group as compared to Diclofenac group. The difference was found to be statistically significant at all point of time post op. Adverse effect like nausea, vomiting and dizziness was seen more among Diclofenac group as compared to Paracetamol group.

Conclusions: Intravenous Paracetamol use was found to be associated with better postoperative pain relief and reduced need for rescue analgesia consumption in the postoperative period.
\end{abstract}

Keywords: Diclofenac, Pain, Paracetamol, Tramadol, Visual analogue score

\section{INTRODUCTION}

Innervation of the urogenital tract is complex and made up of somatic, sympathetic and parasympathetic components, found along the lateral walls of the pelvis. The nerves and nerve plexuses in the pelvis innervate the organs of the pelvis through the ligaments that anchor the various organs to the pelvis. Innervation to the uterus, ovaries, and vagina is derived from the superior hypogastric, pelvic, and uterovaginal plexus. Hysterectomy is the second most frequently performed major surgical procedures on women all over the world, next only to caesarean section. In US, approximately 600,000 hysterectomies are performed each year. In India, no national statistics for hysterectomy is available. A study conducted in a northern state of India (Haryana) states that incidence of hysterectomy was 7\% among married women above 15 years of age. ${ }^{1}$ Another study from a western state (Gujarat) pointed out that $7-8 \%$ of rural women and $5 \%$ of urban women had already undergone hysterectomy at an average age of 37 years. Indications of hysterectomy vary from genital 
malignancies to benign conditions such as uterine leiomyma, abnormal uterine bleeding, and pelvic organ prolapse. ${ }^{2}$ As any other surgery, hysterectomy is also associated with intra operative and post operative complications.

Pain in the post-operative period is a critical factor that impedes recovery from surgery and anaesthesia. Abdominal hysterectomy is associated with moderate-tosevere postoperative pain, which has unfavourable effects on patient's recovery and procedure's outcome. Effective analgesia is important for early ambulation and postoperative hospital stay, thereby reducing the burden on patient's health and pocket.3Hence, management of post-operative pain is of utmost importance for early ambulation and discharge reducing the days of hospital stay. Opioid analgesics are the traditional first-line medication in this setting but may induce unwanted side effects, such as nausea and vomiting, sedation, and respiratory depression. Several studies have shown that non-opioid analgesics (Paracetamol, NSAIDs) provide effective pain relief in patients with acute postoperative pain, either as a substitute for or as an adjunct to opioid analgesia.

This study was done to compare the effectiveness of intravenous Paracetamol and intramuscular Diclofenac when used for post-operative pain control in abdominal hysterectomy (AH) patients and compare the need for rescue analgesia (Tramadol) in both the groups.

\section{METHODS}

Study design: prospective observational and clinically randomized study.

Place of study: Department of Obstetrics and Gynaecology, Government Medical College Haldwani and associated Dr. Shushila Tiwari Government Hospital, Haldwani.

Sample size: 60 patients in each group.

Period of study: January 2019 to September 2020 after getting clearance from the ethical committee.

\section{Inclusion criteria}

Patients undergoing elective abdominal hysterectomy for

Dysfunctional uterine bleeding, Uterine fibroid,

Adenomyosis

\section{Exclusion criteria}

History of hypersensitivity to Paracetamol, Tramadol or Diclofenac. History of usage of Paracetamol, opioids, or NSAIDs in the 48 hours before requiring chronic analgesic treatment. Chronic alcoholism. Diseases of kidney, liver. Cardiovascular system illness. Bleeding diathesis. ASA grade III and IV patients.

\section{Methodology}

All patients willing for surgery were enrolled as participants in the study. Written consent was obtained. At first counselling, the patients were given an explanation about the study. Patients were divided into two groups of 60 each by simple randomization on an alternate basis. The patients were blinded to the group allocation. Thorough history was taken, general and systemic examination was done. Any contraindication to the use of acetaminophen, Diclofenac and Tramadol was noted and such patients were excluded from the study. Two hours after giving spinal anaesthesia, one group of patients- group A received acetaminophen(Paracetamol) $1000 \mathrm{mg}$ (100ml infusion) intravenous followed by subsequent doses of intravenous acetaminophen at the dose of $1000 \mathrm{mg}$ every 8 hourly for $48 \mathrm{hrs}$ and group B received injection Diclofenac $75 \mathrm{mg}$ intramuscular every 8 hourly for $48 \mathrm{hrs}$. Pain intensity of patients was noted 2 hourly for 6 hours after giving the first dose of the drug and then at every 8 hour for next 48 hours, using VAS scoring. Pt's hemodynamics in form of respiratory rate, heart rate, mean arterial pressure (MAP), oxygen saturation (sPO2) were monitored as per pain monitoring protocol.

Injection Tramadol $50 \mathrm{mg}$ intravenous was used as rescue drug. All patients were monitored for side effects in form of nausea, vomiting, allergic reactions (itching or rashes) and dizziness.

\section{Statistical analysis}

The sample size estimation for the study is based on earlier studies on hysterectomies. Results are shown as mean and standard deviation (SD) or medians and interquartiles for numerical variables and as numbers and percentages for categorical variables. Independent sample t-test was used to analyse normally distributed continuous variables. Mann-Whitney was used to analyse skewly distributed continues variables. Chi-Square or Fisher's exact test were used to assess differences in categorical variables. Repeated measures of ANOVA were used. Differences between groups were considered significant at $\mathrm{P}<0.05$. The statistical analysis was performed using SPSS $^{\mathrm{TM}}$, Windows version 16.0 (SPSS Inc).

\section{RESULTS}

Table 1 shows that majority of the participants were in the age group <45years in both the groups.

Table 2 shows that maximum number of study participants in both the groups were from rural area (51.7\% and $53.3 \%$ respectively) as compared to urban area. 
Table 1: Distribution of study participants in the two group according to age.

\begin{tabular}{|c|c|c|c|c|c|}
\hline \multirow{2}{*}{$\begin{array}{l}\text { Age } \\
\text { Group }\end{array}$} & \multicolumn{2}{|c|}{$\begin{array}{l}\text { I.V } \\
\text { Paracetamol }\end{array}$} & \multicolumn{2}{|c|}{$\begin{array}{l}\text { I.M } \\
\text { Diclofenac }\end{array}$} & \multirow{2}{*}{$\begin{array}{l}\text { Tot } \\
\text { al }\end{array}$} \\
\hline & No. & $\%$ & No. & $\%$ & \\
\hline$<45$ years & 34 & 56.7 & 33 & 55.0 & 67 \\
\hline$\geq 45$ years & 26 & 43.3 & 27 & 45.0 & 53 \\
\hline Total & 60 & 100.0 & 60 & 100.0 & 120 \\
\hline
\end{tabular}

Table 2: Distribution of study participants in the two group according to demographic area.

\begin{tabular}{|c|c|c|c|c|c|}
\hline \multirow{2}{*}{$\begin{array}{l}\text { Demograph } \\
\text { ic Area }\end{array}$} & \multicolumn{2}{|c|}{$\begin{array}{l}\text { I.V } \\
\text { Paracetamol }\end{array}$} & \multicolumn{2}{|c|}{$\begin{array}{l}\text { I.M } \\
\text { Diclofenac }\end{array}$} & \multirow{2}{*}{$\begin{array}{l}\text { Tot } \\
\text { al }\end{array}$} \\
\hline & No. & $\%$ & No. & $\%$ & \\
\hline Rural & 31 & 51.7 & 32 & 53.3 & 63 \\
\hline Urban & 29 & 48.3 & 28 & 46.7 & 57 \\
\hline Total & 60 & 100.0 & 60 & 100.0 & 120 \\
\hline
\end{tabular}

Table 3: Distribution of study participants in the two group according to ASA (American Society of Anaesthesiology) grade.

\begin{tabular}{|c|c|c|c|c|c|}
\hline \multirow{2}{*}{$\begin{array}{l}\text { ASA } \\
\text { Grade }\end{array}$} & \multicolumn{2}{|c|}{$\begin{array}{l}\text { I.V } \\
\text { Paracetamol }\end{array}$} & \multicolumn{2}{|c|}{$\begin{array}{l}\text { I.M } \\
\text { Diclofenac }\end{array}$} & \multirow{2}{*}{$\begin{array}{l}\text { Tot } \\
\text { al }\end{array}$} \\
\hline & No. & $\%$ & No. & $\%$ & \\
\hline I & 24 & 40.0 & 24 & 40.0 & 48 \\
\hline II & 36 & 60.0 & 36 & 60.0 & 72 \\
\hline Total & 60 & 100.0 & 60 & 100.0 & 120 \\
\hline
\end{tabular}

Table 3 shows that majority of the paticipants in both the group were in ASA grade II $(60.0 \%$ and $60.0 \%$ respectively).

Table 4: Comparison of mean baseline parameters among the two groups.

\begin{tabular}{|llllll|}
\hline & \multicolumn{4}{l}{ IV } & \multicolumn{3}{l|}{ IM Diclofenac } & \multicolumn{1}{l|}{ p } \\
& Paracetamol & \multicolumn{2}{l|}{} & \\
& Mean & SD & Mean & SD & Value \\
\hline Age & 42.81 & 7.12 & 42.85 & 7.14 & 0.98 \\
\hline Weight & 66.07 & 8.39 & 65.30 & 10.39 & 0.66 \\
\hline $\begin{array}{l}\text { Duration } \\
\text { of } \\
\text { Surgery }\end{array}$ & 53.53 & 4.58 & 53.67 & 4.63 & 0.87 \\
\hline
\end{tabular}

Table 4 shows that the the mean age was $42.81 \pm 7.12$ years, mean weight was $66.07 \pm 8.39 \mathrm{Kg}$ and mean duration of surgery was $53.53 \pm 4.58$ minutes in Paracetamol group. In the Diclofenac group mean age was $42.85 \pm 7.14$ years, mean weight was $65.30 \pm 10.39 \mathrm{Kg}$ and mean duration of surgery was $53.67 \pm 4.63$ minutes respectively. The mean difference for the above mentioned variables were found to be non-significant among the two groups.
Table 5: Comparison of VAS (Visual Analogue Scale) score post-op at different points of time among the two group.

\begin{tabular}{|c|c|c|c|c|c|}
\hline \multirow[t]{2}{*}{ VAS } & \multicolumn{2}{|c|}{$\begin{array}{l}\text { I.V } \\
\text { Paracetamol }\end{array}$} & \multicolumn{2}{|c|}{ I.M Diclofenac } & \multirow{2}{*}{$\begin{array}{l}\mathbf{p} \\
\text { Value }\end{array}$} \\
\hline & Mean & SD & Mean & SD & \\
\hline T2 & 5.83 & 0.99 & 6.70 & 0.96 & 0.001 \\
\hline T4 & 5.80 & 0.99 & 6.50 & 0.87 & 0.001 \\
\hline T6 & 4.43 & 0.77 & 5.20 & 0.99 & 0.001 \\
\hline T8 & 4.85 & 0.52 & 5.93 & 0.36 & 0.001 \\
\hline T16 & 2.55 & 0.98 & 3.30 & .96 & 0.001 \\
\hline T24 & 2.90 & 0.54 & 4.00 & 0.00 & 0.001 \\
\hline T32 & 2.88 & 0.61 & 3.67 & 0.84 & 0.001 \\
\hline T40 & 2.77 & 0.56 & 3.97 & 0.69 & 0.001 \\
\hline T48 & 2.17 & 0.78 & 3.10 & 1.00 & 0.001 \\
\hline
\end{tabular}

Table 5 shows that the post-op mean VAS score at different point of time among the two treatment group was lower for paracetamol group as compared to diclofenac group. The difference was found to be statistically significant at all point of time post op.

Table 6: Comparison of respiratory rate $(\mathrm{RR})$ post-op at different points of time among the two groups.

\begin{tabular}{|llllll|}
\hline & \multicolumn{2}{l}{$\begin{array}{l}\text { I.V } \\
\text { Raracetamol }\end{array}$} & \multicolumn{2}{l|}{ I.M Diclofenac } & p \\
& Mean & SD & Mean & SD & Value \\
\hline T2 & 13.77 & 1.14 & 13.78 & 1.18 & 0.94 \\
\hline T4 & 13.60 & 0.49 & 13.60 & 0.49 & 1.00 \\
\hline T6 & 13.82 & 0.50 & 13.80 & 0.40 & 0.84 \\
\hline T8 & 13.80 & 0.40 & 13.82 & 0.39 & 0.82 \\
\hline T16 & 13.43 & 0.49 & 13.38 & 0.49 & 0.58 \\
\hline T24 & 13.22 & 0.42 & 13.20 & 0.40 & 0.82 \\
\hline T32 & 13.03 & 0.18 & 13.00 & 0.00 & 0.16 \\
\hline T40 & 13.42 & 0.49 & 13.42 & 0.49 & 1.00 \\
\hline T48 & 12.70 & 1.72 & 12.92 & 0.28 & 0.34 \\
\hline
\end{tabular}

Table 7: Comparison of MAP (mean arterial pressure) post-op at different points of time among the two groups.

\begin{tabular}{|llllll|}
\hline \multirow{2}{*}{ MAP } & \multicolumn{2}{l}{ I.V } & \multicolumn{4}{l|}{ I.M Diclofenac } & p \\
& Mean & SD & Mean & SD & Value \\
\hline T2 & 83.87 & 2.88 & 85.03 & 3.11 & 0.04 \\
\hline T4 & 82.53 & 2.92 & 84.27 & 3.07 & 0.002 \\
\hline T6 & 84.33 & 0.75 & 84.33 & 0.75 & 1.00 \\
\hline T8 & 83.13 & 0.99 & 83.07 & 1.00 & 0.72 \\
\hline T16 & 82.07 & 1.84 & 82.17 & 1.85 & 0.77 \\
\hline T24 & 83.17 & 2.16 & 83.03 & 2.16 & 0.74 \\
\hline T32 & 84.80 & 3.17 & 84.83 & 3.15 & 0.95 \\
\hline T40 & 82.13 & 1.84 & 82.10 & 1.86 & 0.92 \\
\hline T48 & 80.00 & 0.00 & 80.00 & 0.00 & - \\
\hline
\end{tabular}


Table 6 shows that the post-op mean respiratory rate at different point of time among the two treatment group was almost equal at all point of time. No Statistically significant difference was seen for mean respiratory rate at any point of time between the two group.

Table 7 shows that the post-op mean MAP at different point of time among the two treatment group was almost equal at all point of time except at $\mathrm{T} 2$ and $\mathrm{T} 4$ where it was significantly higher for Diclofenac group as compared to Paracetamol group.

Table 8: Comparison of Pulse rate post-op at different points of time among the two groups.

\begin{tabular}{|c|c|c|c|c|c|}
\hline \multirow{2}{*}{$\begin{array}{l}\text { Pulse } \\
\text { rate }\end{array}$} & \multicolumn{2}{|c|}{$\begin{array}{l}\text { IV } \\
\text { Paracetamol }\end{array}$} & \multicolumn{2}{|c|}{ IM Diclofenac } & \multirow{2}{*}{$\begin{array}{l}\text { p } \\
\text { Value }\end{array}$} \\
\hline & Mean & SD & Mean & SD & \\
\hline $\mathbf{T} 2$ & 92.00 & 9.29 & 92.23 & 9.26 & 0.89 \\
\hline T4 & 90.00 & 8.56 & 90.20 & 8.51 & 0.89 \\
\hline T6 & 90.00 & 8.36 & 90.30 & 8.25 & 0.84 \\
\hline T8 & 90.40 & 90.58 & 90.77 & 9.44 & 0.83 \\
\hline T16 & 90.80 & 7.50 & 90.97 & 7.37 & 0.90 \\
\hline T24 & 88.00 & 5.98 & 87.97 & 5.99 & 0.98 \\
\hline T32 & 87.60 & 4.67 & 87.70 & 4.95 & 0.97 \\
\hline T40 & 87.60 & 5.01 & 87.70 & 4.95 & 0.91 \\
\hline T48 & 85.60 & 5.62 & 85.63 & 5.61 & 0.97 \\
\hline
\end{tabular}

Table 8 shows that the post-op mean pulse rate at different point of time among the two treatment group was almost equal at all point of time. No Statistically significant difference was seen for mean pulse rate at any point of time between the two group.

Table 9: Comparison of $\mathrm{SpO} 2$ post-op at different points of time among the group.

\begin{tabular}{|c|c|c|c|c|c|}
\hline \multirow[t]{2}{*}{ Spo2 } & \multicolumn{2}{|c|}{$\begin{array}{l}\text { I.V } \\
\text { Paracetamol }\end{array}$} & \multicolumn{2}{|c|}{ I.M Diclofenac } & \multirow{2}{*}{$\begin{array}{l}\mathbf{p} \\
\text { Value }\end{array}$} \\
\hline & Mean & SD & Mean & SD & \\
\hline T0 & 99.45 & 0.65 & 99.45 & 0.65 & 1.00 \\
\hline T2 & 98.80 & 0.82 & 98.80 & 0.78 & 1.00 \\
\hline T6 & 98.67 & 1.39 & 98.88 & 1.18 & 0.36 \\
\hline T8 & 98.63 & 1.04 & 98.68 & 0.99 & 0.79 \\
\hline T16 & 98.45 & 0.75 & 98.53 & 0.65 & 0.52 \\
\hline T24 & 98.35 & 1.04 & 98.48 & 0.99 & 0.48 \\
\hline T32 & 98.35 & 1.01 & 98.37 & 1.07 & 0.93 \\
\hline T40 & 98.90 & 89 & 99.00 & 0.84 & 0.53 \\
\hline T48 & 99.00 & 0.88 & 98.97 & 0.88 & 0.84 \\
\hline
\end{tabular}

Table 9 shows that the post-op mean spo2 at different point of time among the two treatment group was almost equal at all point of time. No Statistically significant difference was seen for mean SPO2 at any point of time between the two group.

Table 10 shows that the adverse effect like nausea, vomiting and dizziness was seen more among diclofenac group as compared to paracetamol group, however the difference was not statistically significant. Equal number of patients in both groups developed itching.

Table 10: Comparison of adverse effects post-op among the two group.

\begin{tabular}{|c|c|c|c|c|c|c|c|}
\hline \multirow{2}{*}{ Adverse Effect } & & \multicolumn{2}{|c|}{ IV Paracetamol } & \multicolumn{2}{|c|}{ IM Diclofenac } & \multirow{2}{*}{ Total } & \multirow{2}{*}{ p Value } \\
\hline & & No. & $\%$ & No. & $\%$ & & \\
\hline \multirow{2}{*}{ Nausea } & Yes & 14 & 23.3 & 19 & 31.7 & 33 & \multirow{2}{*}{0.31} \\
\hline & No & 46 & 76.7 & 41 & 68.3 & 87 & \\
\hline \multirow{2}{*}{ Vomiting } & Yes & 9 & 15.0 & 12 & 20.0 & 21 & \multirow{2}{*}{0.47} \\
\hline & No & 51 & 85.0 & 48 & 80.0 & 99 & \\
\hline \multirow{2}{*}{ Itching/ Rashes } & Yes & 2 & 3.3 & 2 & 3.3 & 4 & \multirow{2}{*}{1.00} \\
\hline & No & 58 & 96.7 & 58 & 96.7 & 116 & \\
\hline \multirow{2}{*}{ Dizziness } & Yes & 3 & 5.0 & 6 & 10.0 & 9 & \multirow{2}{*}{0.29} \\
\hline & No & 57 & 95.0 & 54 & 90.0 & 111 & \\
\hline
\end{tabular}

Table 11: Comparison of rescue analgesia post-op among the two group.

\begin{tabular}{|lllllll|}
\hline \multirow{2}{*}{ Rescue Analgesia } & \multicolumn{2}{l}{ IV Paracetamol } & \multicolumn{2}{c|}{ IM Diclofenac } & Total & p Value \\
\cline { 2 - 6 } & No. & \% & No. & \% & 25 & \\
Yes & 6 & 10.0 & 19 & 31.7 & 0.003 \\
\hline No & 54 & 90.0 & 41 & 68.3 & 64 & \\
\hline Total & 60 & 100.0 & 60 & 100.0 & 120 & \\
\hline
\end{tabular}

Table 11 sows that rescue analgesia was required in $10 \%$ of patients in paracetamol group while it was required in
$31.7 \%$ of patients in diclofenac group and this difference was found to be statistically significant. 


\section{DISCUSSION}

Pain in the post-operative period is an emotional and mental trauma with unpleasant sensory experience. Pain if inadequately relieved can result in various complications like atelectasis/ pneumonitis/ hypoxemia, deep vein thrombosis, delayed recovery of bowel function, myocardial ischemia and infarction, urinary retention and residual psychological trauma. Conversely, adequate pain relief reduces patients' anxiety, morbidity, and duration of hospitalization, along with the associated costs of care ${ }^{4}$.

In our study we found that;

\section{Sociodemographic feature}

In our study majority of the participants were in the age group <45years in both the groups. Mean age was $42.81 \pm 7.12$ years, mean weight was $66.07 \pm 8.39 \mathrm{Kg}$ and mean duration of surgery was $53.53 \pm 4.58$ minutes in Paracetamol group. In the Diclofenac group mean age was $42.85 \pm 7.14$ years, mean weight was $65.30 \pm 10.39 \mathrm{Kg}$ and mean duration of surgery was $53.67 \pm 4.63$ minutes respectively. No Significant difference was seen for the duration of surgery among the two groups. Similar findings were observed by Sede SS et al, Nader N et al, Arora Trivedi $\mathrm{P}$ et al and $\mathrm{Pal} \mathrm{A}$ et al. Maximum number of study participant in both the groups was from rural area $(51.7 \%$ and $53.3 \%$ respectively) as compared to urban area. ${ }^{5-7}$

\section{Mean VAS score}

Majority of the participants in both the groups were in ASA (American Society of Anaesthesiology) grade II (60.0\% and $60.0 \%$ respectively). In a similar study by Paul D et al showed that patients under ASA I administrating was 20 in Paracetamol group and 22 in diclofenec group while patients under ASA II was 10 in Paracetamol group and 8 in diclofenec group. ${ }^{8}$

In our study post-op mean VAS score at different point of time among the two treatment groups was lower for Paracetamol group as compared to Diclofenac group. The difference was found to be statistically significant at all point of time post op.

Similar results were observed by Thorat D.P et al they found that with passage of time there is decrease in the VAS in all the groups of Paracetamol and Diclofenac and at 24 hours the VAS values are zero in all the patient groups, showing the effectiveness of both thedrugs as analgesics for mild to moderate pain, but there is increase in VAS values of both the groups of Diclofenac in the time interval of 5-12 hrs period postoperatively probably due to wearing off effect ofthe drug during this interval. S Aghamir et al showed that Paracetamol could be considered as a safe alternative post-operatively for pain management after urologic surgery when compared to
Tramadol, however its use for severe pain management leads to inefficient pain control, necessitating supplementary analgesics. While study by Rani $\mathrm{K}$ et al showed that Paracetamol is equally effective for postoperative pain and need of additional analgesic is comparable in both groups..$^{9-11}$ Muhammad Asghar Ali in a comparative study between intravenous Paracetamol and fentanyl for intraoperative and postoperative pain relief in dilatation and evacuation and demonstrated the usefulness of IV Paracetamol which may be as effective as fentanyl in dilation and curettage procedures. ${ }^{12}$ Findings of study by Abinaya A et al propose that Paracetamol group had a considerable decrease in pain intensity one and three hours after drug administration in comparison to intramuscular Tramadol. ${ }^{13}$ Study done by Ayan $M$ et al in the year 2013 in emergency room with cases of primary dysmenorrhea. ${ }^{14}$ Following treatment, in the 10th and 30th minutes, the scores were lower in Paracetamol group compared to Diclofenac $(p=0.00)$ hence showed Paracetamol is more efficient than Diclofenac in the treatment of primary dysmenorrhea. Dissimilar to our results study by Agrawal SA et al found that Paracetamol Group showed a significant change in its Median VAS score from immediate postoperative period till 48 hour in its own group of patients $(p<0.05)$. Similar results were seen with Diclofenac Group also i.e. reduction of all the three time based scores were statistically significant compared to the baseline score within the group itself $(\mathrm{p}<0.05) .{ }^{15}$ However when we compared the VAS scores between the 2 Groups at different time intervals, it showed that at 24 hours and 48 hours VAS score in the Diclofenac Group was significantly less than the Paracetamol Group. It means at 24 hour and 48 hour pain reduction is more in the Diclofenac group as compared to Paracetamol group. Goel et al in their comparative study for pre-emptive analgesia with IV Paracetamol and IV Diclofenac sodium in patients undergoing various surgical procedures found that mean pain score is higher in the Diclofenac group for the initial period followed by insignificant difference in pain score for $4 \mathrm{hrs} .^{16}$

\section{Effect on respiratory rate and pulse rate}

Post-op mean respiratory rate at different point of time among the two treatment group was almost equal at all point of time. No Statistically significant difference was seen for mean respiratory rate at any point of time between the two groups. Post-op mean pulse rate at different point of time among the two treatment group was almost equal at all point of time. No Statistically significant difference was seen for mean pulse rate at any point of time between the two groups. While comparing the pulse rate Paul $\mathrm{D}$ et al found that there is no statistically significant variation in both the groups while Goel et al in their comparative study for pre- emptive analgesia with I.V Paracetamol and I.V Diclofenac sodium in patients undergoing various surgical procedures found that pulse rate was almost equal to base line value in both the groups. ${ }^{8,16}$ But in their study they 
had found significant variation in mean changes between the groups whereas in our study, both the groups are comparable.

Thorat D.P et al also found that In Paracetamol groups i.e. both in spontaneously breathing group and controlled ventilation group, mean SBP values are less in each time interval when compared with the Diclofenac groups. ${ }^{9}$ This shows the more effectiveness of Paracetamol when compared with Diclofenac for postoperative mild to moderate pain, seen clinically as well as proved statistically. With passage of each time interval there is decrease in the SBP in all the groups of Paracetamol and Diclofenac showing the effectiveness of both the drugs as analgesics, but there is increase in the SBP in both the groups of Diclofenac in the time interval of 5-12 hrs postoperatively because of wearing off effect of the drug during this period. Similar findings are seen while comparing DBP and Pulse rate between different groups with SBP. While comparing the SBP, DBP and MAP in both the groups Paul et al have observed that there is no significant variation in both the groups in different intervals except the mean values for DBP at $12 \mathrm{hr}$ of postoperative period where it was found that DBP is higher in the Diclofenac group. ${ }^{8}$

The difference in mean values is statistically significant.

\section{Mean arterial pressure and SPO2}

Post-op mean MAP at different point of time among the two treatment group was almost equal at all point of time except at 0 and 2 hours post-op where it was significantly higher for Diclofenac group as compared to Paracetamol group. Post-op mean sPO2 at different point of time among the two treatment group was almost equal at all point of time. No Statistically significant difference was seen for mean $\mathrm{sPO} 2$ at any point of time between the two groups.

\section{Adverse effects}

Adverse effect like nausea, vomiting and dizziness was seen more among Diclofenac group as compared to Paracetamol group, however, the difference was not statistically significant. Equal number of patients in both groups developed itching. In study by Rani K et al out of fifty patients $(8 \%)$ in Paracetamol group (two patients had nausea, one had dizziness and one had vomiting) had side effects. ${ }^{11}$ Similar results were observed by Paul D et al that patients in the Diclofenac group had more incidences of complications like nausea and vomiting and in Paracetamol group, there is not a single case of postoperative complication whereas in Diclofenac group, total number of patients requiring management for postoperative complications is $04(13.33 \%) .{ }^{8}$ Elbohoty et al compared intravenous Paracetamol infusion with intravenous pethidine as labour analgesia. ${ }^{17}$ It has been concluded that effectiveness of intravenous Paracetamol and duration of action are similar in each drugs, but
Paracetamol was associated with fewer maternal adverse outcomes than pethidine. In a prospective double blind randomized placebo controlled study conducted by Cakan et al on 40 patients undergoing lumbar laminectomy and discectomy, it was demonstrated that IV Paracetamol decreased visual analog scale scores and incidence of vomiting and had better patient satisfaction. ${ }^{18}$

\section{Rescue analgesia}

Rescue analgesia was required in $10 \%$ of patients in Paracetamol group while it was required in $31.7 \%$ of patients in Diclofenac group and this difference was found to be statistically significant. Moon et al randomized 76 patients undergoing abdominal hysterectomy to receive $2 \mathrm{~g}$ IV acetaminophen or placebo 30 minutes prior to surgery; postoperative pain was measured by VAS score and PCA hydromorphone consumption was quantified by group. ${ }^{19}$ They found IV acetaminophen to have an opioid-sparing effect when compared with placebo, as this present study did when comparing IV acetaminophen with Ketamine.

Cobby et al compared acetaminophen to another NSAID, Diclofenac, an analgesic class for which the comparative efficacy was evaluated in our study and found that the recovery room, intravenous PCA pumps with a $1 \mathrm{mg}$ Morphine bolus, a 5-minute lockout interval, and no basal infusion were administered to all patients. ${ }^{20}$ The required amount of Morphine was significantly lower in the acetaminophen and Diclofenac groups than in the placebo group. Varrassi et al randomly allocated 200 women aged 18-70 years to two groups to receive either $1 \mathrm{~g}$ acetaminophen or $30 \mathrm{mg}$ Ketorolac (NSAID) intravenously at extubation. ${ }^{21}$ During a 12-hour postoperative monitoring period, they concluded that acetaminophen is as effective as Ketorolac in controlling pain after gynecological procedures. Nader $\mathrm{N}$ et al found that IV acetaminophen to be more effective than IV Ketamine administered intraoperatively for pain management after the abdominal hysterectomy. ${ }^{6}$ Moreover, there was a significant decrease in the administration of breakthrough analgesics (Meperidine) in the IV acetaminophen group compared to the IV Ketamine group. Munishankar B concluded that Patients given a combination of Diclofenac and Paracetamol used $38 \%$ less Morphine compared to patients given Paracetamol after caesarean section while in our study pain relief was adequate with Paracetamol alone indicating no additional benefit of combination therapy. ${ }^{22}$ Study by Paul D et al observed that in Paracetamol group, there were only 3 patients for whom Morphine was administered and 27 patients $(90.0 \%)$ did not require rescue analgesia in Diclofenac group, 8 patients required administration of Morphine and 22 patients (73.9\%) were without rescue analgesia. ${ }^{8}$ This difference was found statistically significant. Similar finding was postulated by the study by Goel et al in their comparative study for preemptive analgesia with IV Paracetamol and IV Diclofenac sodium in patients undergoing various 
surgical procedures. ${ }^{16}$ Observations were mentioned in Health Technology Assessment 2010 that while comparing Paracetamol and NSAID that the adjustment of the 24-hour Morphine consumption model. The treatment effect estimates of NSAIDs and Paracetamol became closer. The adjusted analysis did show a greater reduction in Morphine consumption with Paracetamol.

\section{CONCLUSION}

Intravenous Paracetamol use was found to be associated with better postoperative pain relief and reduced need for rescue analgesia consumption in the postoperative period. The side effects were negligible for both the drugs.

Funding: No funding sources

Conflict of interest: None declared

Ethical approval: The study was approved by the Institutional Ethics Committee

\section{REFERENCES}

1. Brummer THI, Jalkanen J, Fraser J, Heikkinen AM, Kauko M, Mäkinen J, et al. FINHYST 2006 national prospective 1-year survey of 5279 hysterectomies. Hum Reprod. 2009;24:2515.

2. Kovac S. Route of hysterectomy: An evidence-based approach. Clin Obstet Gyn. 2014;57:58-71.

3. Pogatzki Zahn EM, Zahn PK, Brennan TJ. Postoperative pain-clinical implications of basic research. Best Pract Research Clinical Anaesthesiol. 2007;21:3-13.

4. Ip HYV, Abrishami A, Peng PW, Wong J, Chung F. Predictors of postoperative pain and analgesic consumption: A qualitative systematic review. Anesthesiol. 2009;111:657-77.

5. Sede SS, Tanha FD, Valadan M, Modaressi Z. Comparison between preoperative rectal diclofenac plus paracetamol and diclofenac alone for postoperativepain of hysterectomy. J Family Reproductive Health. 2014;8(3):91.

6. Faiz HR, Rahimzadeh P, Visnjevac O, Behzadi B, Ghodraty MR, Nader ND. Intravenous acetaminophen is superior to ketamine for postoperative pain after abdominal hysterectomy: Results of a prospective, randomized, double-blind, multicenter clinical trial. J P Res. 2014;7:65.

7. AroraTrivedi P, Mehta M. A study of efficacy of a single dose of a transdermal diclofenac patch and intramuscular diclofenac-as pre-emptive postoperative analgesia in patients undergoing abdominal hysterectomy. Int $\mathbf{J}$ Res Med. 2015;4(4):96-101.

8. Paul D, Jacob M, Kulkarni SN. Comparative evaluation of efficacy of intravenous paracetamol and intravenous diclofenac as post-operative analgesia in laparoscopic cholecystectomy. Int Jour of Biomed Res. 2015;6(7):482.

9. Thorat, D.P., Singla, D.A., \&Senjalia, D.H. (2017). Comparison of the Efficacy of Intravenous
Paracetamol and Diclofenac for Post-Operative Analgesia. SJAMS. 2017;5(9A):3539-46.

10. Aghamir SK, Mojtahedzadeh M, Alizadeh F, Alizadeh F, Khalili H, Najafi A, et al. Paracetamol Vs. Tramadol for post-operative pain management after urologic surgery. The Internet $\mathbf{J}$ of Pharmacology. 2005;4:2.

11. Rani K, Zutshi V, Patel M, Marwah S. Analgesic efficacy of intravenous paracetamol versus intravenous tramadol after caesarean section: a single blind randomized controlled study. Int $\mathrm{J}$ ReprodContraceptObstet Gynecol. 2016;4285-9.

12. Ali MA, Shamim F, Chughtai S. Comparison between intravenous Paracetamol and fentanyl for intraoperative and postoperative pain relief in dilatation and evacuation. Journal of Anaesthesiology Clinical Pharmacol. 2015;31:54-8.

13. Abinaya A, Latha K, Jayashree V. Comparative study between intravenous paracetamol and intramuscular tramadol as labour analgesia. Int $\mathrm{J}$ Current Med Pharma Res. 2017;3(10).

14. Ayan M, Taş U, Söğüt E, Arıcı S, Karaman S, Esen $M$, et al. Comparing efficiencies of Diclofenac sodium and Paracetamol in patients with primary dysmenorrhea pain by using Visual Analog Scale. Agri. 2013;25(2):78-82.

15. Agrawal SA, Nikhate SD, Thakur MM, Bal H. A study of comparison of efficacy and side effects of intravenous paracetamol and intravenous diclofenac as a postoperative analgesic. Int J Reprod Contracept Obstet Gynecol. 2019;8(9):3684.

16. Goel P. Pre emptive analgesia with iv Paracetamol and iv Diclofenac sodium in patients undergoing various surgical procedures: a comparative study Int J Biol Med Res. 2013;4(3):3294-300.

17. Elbohoty AE, Abd-Elrazek H, Abd-El-Gawad M. Intravenous infusion of Paracetamol versus intravenous Pethidine as an intrapartum analgesic in the first stage of labor. Int $\mathbf{J}$ Gynaecol Obstet. 2012;118:7-10.

18. Turkay C, Nurten I, Safiye C. Intravenous Paracetamol Improves the Quality of Postoperative Analgesia but Does not Decrease Narcotic Requirements. Journal of Neurosurgical Anesthesiol. 2008;20(3):169-73.

19. Moon YE, Lee YK, Lee J, Moon DE. The effects of preoperative intravenous acetaminophen in patients undergoing abdominal hysterectomy. Arch Gynecol Obstet. 2011;284(6):1455-60.

20. Cobby TF, Crighton IM, Kyriakides K, Hobbs GJ. Rectal paracetamol has a significant morphinesparing effect after hysterectomy. Br J Anaesth. 1999;83(2):253-6.

21. Varrassi G, Marinangeli F, Agrò F. A double-blinded evaluation of propacetamol versus ketorolac in combination with patient-controlled analgesia morphine: analgesic efficacy and tolerability after gynecologic surgery. Anesth Analg. 1999;88(3):6116. 
22. Munushenkar B, Fettes P, Moore C, Mcleod GA. A double-blind randomized controlled trial of paracetamol, diclofenac or the combination for pain relief after caesarean section. International Journal of Obstetric Anesthesia. 2008;17:9-14.

23. McDaid C, Maund E, Rice S, Wright K, Jenkins B, Woolacott N. Health Technology Assessment, Paracetamol and selective and non-selective nonsteroidal anti-inflammatory drugs (NSAIDs) for the reduction of morphine-related side effects after major surgery: A systematic review 2010;14:17.

Cite this article as: Bisht $\mathrm{P}$, Jain $\mathrm{G}$. Comparison of intravenous paracetamol vs. intramuscular diclofenac for postoperative pain control in abdominal hysterectomy. Int J Reprod Contracept Obstet Gynecol 2021;10:1525-32. 